\title{
Repurposing Post Offices as Community Innovation Hubs: Digital Inclusion, Equity and De- concentration
}

\author{
Michael Gurstein, Ph. D.
}

Editor, the Journal of Community Informatics

gurstein@gmail.com

This will be my last formal "editorial" as Editor in Chief of the Journal of Community Informatics. As of this issue I am passing the torch along to my long-time friends and colleagues (and former and current JoCI Associate Editors) Eduardo Villanueva-Mansilla, Associate Professor at the Communications Department, Pontificia Universidad Católica del Perú, who will be joined as coEditor (after Jan. 1,2017) by Dr. Susan O’Donnell, Sociology Department, University of New Brunswick, Fredericton, NB, Canada.

I have absolutely no doubt that they will carry on with the strengths of JoCI while moving it into new areas and with renewed energy and creativity.

It has been my extreme pleasure to work with the larger JoCI community over the last 11 years - the 6000 or so subscribers, the 600 or so registered reviewers, the some $100+$ authors, and the some 50 or so members of the Editorial and Advisory Boards. Together we have done something quite remarkable which is to launch a high quality, internationally recognized journal in a brand new field and with a mandate to be relevant and of interest not only to academics and researchers but also to practitioners and policy makers. That we have had some 2.7 million "article views" since 2006 is a quite amazing result even if I don't quite understand how this has been possible or what impact it might be having.

So thanks to one and all and I look forward to many further years of our mutual engagement with the opportunities and responsibilities of making Information and Communications Technologies relevant and useful to enabling and empowering local communities.

Canada has a new and socially active government after 10 years of darkness and regression under our former Conservative Prime Minister. Among the areas that they have signaled (and provided budgetary support for) is the extension of Broadband Internet capability into Canada's rural and remote regions. As well, the government has begun making steps towards broadening the base of social equity including for Indigenous people and for lower and middle income families. And finally, the government has indicated a strong interest in "innovation" as the basis for building a productive Canadian economy for the future.

Gurstein, M. (2016). Repurposing post offices as community innovation hubs: digital inclusion, equity and de-concentration. The Journal of Community Informatics, 12 (1), 1-6.

Copyright (C), 2016 (the authors as stated). Licensed under the Creative Commons AttributionNonCommercial-ShareAlike 2.5. Available at: www.ci-journal.net/index.php/ciej/article/view/1314 
I think it is possible to link all of these aspirations into a broad based social and technology policy which I'm calling "Inclusion, Equity and De-concentration" and focusing this around what I am calling Community Innovation Hubs (CIHs).

The extension of an infrastructure platform as the basis for Broadband Internet access is an important step in the process of ensuring social inclusion of those who currently are denied effective Internet access and use because of where they live and the lack of an affordable means for internet delivery. However, infrastructure provision is only one element in enabling a broad base of inclusion. As various studies in Canada and elsewhere have demonstrated, lack of physical access may represent only a relatively limited portion of the some $15-20 \%$ of Canadians who currently don't have access to or use of the Internet. As well, there are issues of the cost of Internet access (including the cost of the associated hardware and software), issues of training and literacy and simple lack of interest (or a failure to identify a need which the Internet would uniquely satisfy as a driver to connect).

It is widely recognized that access and use of the Internet platform is becoming a significant means for social inclusion including through access and communication with friends and family by means of social media, through the expression (and reception) of political messages and an enhanced opportunity for at least some form of participatory activity, through enabling economic activity for many based on the transformation of existing business (and work) models and the development of new ones based on the Internet's functionality. It can almost certainly be asserted that the absence of access and use of the Internet is a significant source of social exclusion in modern society.

As we all have become increasingly aware economic inequality has expanded dramatically in recent times and likely not coincidentally in parallel to the infiltration of the Internet into all aspects of modern life. While the Internet extends opportunities for participation and for certain types of enterprise and employment it equally dramatically undercuts certain skills and employment sectors. This cannot be turned back and the impacts and distributional effects are likely to accelerate rather than diminish. The need then for direct intervention by means of public policy including through enhancing access and use of the Internet to reduce economic inequity, will become increasingly acute.

An Internet platform also provides the opportunity for action at a distance. While this functionality has been used with astonishing effect to facilitate the concentration of business enterprise and activity in certain geographical locales; what has not been explored to any similar extent is the use of the functionality to disperse and decentralize opportunity and activity, to shift activity from the centre to the periphery rather than vice versa.

Thus the initial investment in a program to extend the Internet platform to those currently without such access can be seen as a key and initial element in a broader program for repurposing and integrating social and technology policy, both extending inclusion into previously marginalized populations but as well, beginning a broader transformation for social inclusion, social equity and economic and social de-concentration.

If we can begin from a set of assumptions where a common (broadband) Internet platform is accessible to almost all Canadians (preferably as a human right) we can begin to see this as a basis for broad programs promoting and enabling social inclusion-as for example, the development and delivery of content of specific interest to specific target groups such as the 
elderly, indigenous peoples, youth, recent immigrants and so on. Equally the availability of the universal access platform can provide the basis for activities to mitigate those other factors involved in Internet non-use such as literacy, cost of access and hardware and software, the provision of assistive devices, training for digital and other literacies and so on.

Canada in the late 90's and through the 00's pioneered globally in the provision of community Internet access services through what were called (in Canada) Community Access $\underline{\text { Program sites (CAPs) }}$ and elsewhere called telecentres. As the cost of local Internet access declined rapidly throughout much of Canada the immediate requirement for public access facilities (was perceived) as declining as well and the quite successful (particularly in rural areas) CAP program was allowed to whither and eventually effectively die (although there are still a few remnants hanging on using student internship funding primarily.)

As noted, Canada currently has some $85 \%$ of the population with access to the Internet, however the $15 \%$ not currently having access represent quite a significant number of Canadians. For some it is a question of cost and the current unavailability of free (or very low cost) Internet service (except where available in public libraries) is a still very significant problem. For others it is the cost of purchasing and maintaining a piece of often cranky hardware and software. For others it is a lack of training in how to use computers/the Internet often because of a lack of English/French skills (immigrant population) or low levels of literacy. For still others it is a fear of technology and for still others it is an absence of the mechanical devices that will allow those with particular kinds of disabilities to use computers. If only $10 \%$ of the Canadian population (the figure is generally estimated at twice this) fall into one or another of the categories above we are talking about 3.5 million people in all communities in need of some sort of public Internet access and the attendant support.

The process of achieving broad based digital inclusion is equally a process of beginning a longer term path to economic and social equity as the previously excluded and marginalized are provided with the means for accessing and using the Internet to enhance personal opportunities for interaction, employment and to access social services and supports. And since there is inclusion around the common platform there is the equal possibility of using this platform as the basis for beginning a process of dispersal of the capacity for innovation and of the variety of social and economic opportunities towards the periphery and away from the centre.

The broad trend towards the recognition of Internet access as a human right is in part based on the observation that the absence of Internet access may be a barrier to the exercise of the range of other Human Rights. If in this context we refocus our Internet access conceptualization from how to get the internet out to individual users towards how to enable the universal availability/accessibility/use of Internet access, Internet supports and other services in local communities a number of disparate elements begin to fall into place.

The key to developing such a set of social programmes and initiatives however is to recognize that while the primary mode of accessing the Internet is individual for initiatives in support of digital and social inclusion to be effective the activities involved must be "social" or "group" activities taking place in a common social space rather than simply individuals working off a laptop or a mobile. Thus what is needed at the local level are common points of contact, social or community spaces where individuals can gather for Internet access and 
where they and multiple others can be cost effectively supported in the use of the range of other technology devices and supports.

Earlier (and in its time, effective) iterations of this were the Community Access Centre referred to internationally as telecentres. Telecentres were (or rather are as there are still hundreds of thousands of telecentres operating successfully throughout the Developing World) physical locales, places where Internet could be accessed, which had computers and the requisite software (and often additional supportive hardware) and where other services such as training and computer support was also made available often through student interns (for whom this provided very useful training and job experience).

Times of course have changed however, even as the bulk of the population has been able to get online through primarily individual based devices such as laptops or mobile phones, there has been left a significantly sized residue of people - the elderly, those with literacy issues, the poor, recent immigrants with language difficulties, among others for whom the availability of access is still a difficulty and where alternatives as for example, public libraries may not be sufficient as a supplier since libraries have other priorities and by and large while they have been willing to provide simple Internet access they have not, because of a lack of resources, been able or willing to provide the degree of support and training which many of those looking for access currently require.

Meanwhile the starving of the public sector by various governments in the last decades has led to the demise of many of the other common spaces where Internet access and use might have been localized. (It should be noted here that it is my feeling that the decision that most CAP sites would be located in standalone facilities while evidently politically valuable was in fact a mistake for the long term viability of the individual sites and thus the program as a whole. By saddling sites with the need to generate sufficient revenue (at least notionally) to cover the full cost of local start up and on-going rent and maintenance, the program was insisting that the individual sites would be launched with one (sustainability) arm tied behind their backs.)

As well, the identification of a physical space for a community hub can further the broad agenda of seeing and enabling communities at the local level to support innovation both of value to the local community and as broader contributions regionally and nationally to a culture and a practice of "innovation"

I discussed the notion of "Community Innovation" quite extensively in an earlier blogpost:

There is on the other hand a form of "grassroots innovation" also, understood in the context of social change where innovation is not concerned with enabling competition but rather is concerned with effective adaptation to changing circumstances.

This latter type of innovation might be characterized as "social innovation" or "community innovation" since so much of this type of innovation takes place within the context of communities either of place or of interest where trusted peers are enabled to experiment with established routines and practices to find alternative strategies for accomplishing what might otherwise be routine or conventionalized tasks. This type of "innovation" is not concerned with ensuring opportunities for 
competition in globalized marketplaces but rather in enabling those involved in these communities and often grassroots communities to better undertake the tasks for which they normally have responsibility and for undertaking new tasks as they might become necessary and all within a context of shared community norms, values and goals.

The value of locating a set of services and functions such as those in CAP sites in an ongoing facility where most of the physical and managerial elements would be taken care of by others who had the luxury of on-going institutional (and financial) stability was lost in the manner in which CAP was deployed. The absence of this further meant that the individual sites were totally dependent on the Federal funding program which in turn inhibited their capacity to adapt and respond to changing technology circumstances, public demand and availability of local resources.

Let's take for example the possibility that Post Offices could be repurposed as Community Innovation Hubs (I mention Post Offices in this context because of the Delivering Community Power proposal in this direction which is currently being promoted by the Canadian Union of Postal Workers among others) but we could think about these Community Innovation Hubs (CIH) being located in suitably funded and staffed libraries, schools, community centres or even Legions, local co-ops, AgRep offices and so on.

The "Delivering Community Power proposal" is an intriguing one from this perspective. The wide dispersal of post offices, the fact that they are professionally managed and maintained as physical structures, and their wide acceptance and recognition as community common spaces makes them potentially ideal as places for community commons activities where other such facilities might not be available. And of course, the diminishing utilization of postal services, when combined with the variety of reasons for a necessary if diminished continuation of these services has put their economic viability into question while opening up the obvious need for some alternative sources of activity/revenues.

These CIH's could of course start with the more traditional functions of Community Access Centres-i.e. Internet access, Internet training, computer support and so on. But from there they would begin to respond to the overall technology and social changes of the last 20 years and the possible or likely functionalities that one could envisage being located in the variety of CIH's would include among others:

(1) Internet access facilities including support for new users, training on use and applications, assistive devices for those with disabilities and generally providing a site where Internet access and use will be facilitated and enabled for those currently not using the Internet but with some interest in doing so

(2) A number of local communities are taking the initiative to develop their own locally owned and managed broadband networks in the absence of commercial facilities being made available. A CIH would provide a very suitable local site for these types of activities to be developed and housed.

(3) Community wifi: similarly with Broadband a number of communities have decided (often in conjunction with community broadband) to provide free Internet access via community wifi hubs. A CIH again would provide a very suitable facility to house such a service. 
(4) A central public repository for specialized software and hardware along with training and support in its use. This can be anything from help with photos and photoshop to animation and music production. Such facilities have proven particularly helpful with teenagers and young adults in giving them a site for personal expression (and just hanging out) while also providing some training is useful on-going skills.

(5) A hub to provide digital supports for small business development including help with digital bookkeeping, mentoring in small business e-commerce, help with digitalized machine management and so on and overall to the range of supports and services that are generally available but that may not be widely known in smaller and rural communities.

(6) Providing support for the range of e-Government services. s government services go overwhelming online many people who are not active Internet users or who are unsure of how to maneuver in an online environment require support for these activitiesincluding of course for taxation, for various forms of service or support applications and so on.

(7) Providing support for the range of digitally provided banking (as per the "Delivering Community Power" proposal) and other financial services which equally are going online and where as well, various kinds of in-person support and training may be required.

(8) There are many in communities across Canada-high school and other students, hobbyists, small scale entrepreneurs and inventors interested in "making" their own equipment and devices who have need to access relatively low cost equipment but equipment which they can individually not afford. The development of what is being "the Maker Movement" of those who are looking to "make" technology including the burgeoning activities in "3D printing" as well as use it is now widespread and community hubs where activities of this kind can take place are springing up widely but so far only in major centres.

(9) One of the major problems in the electronic era is electronic waste. There is in most communities a need for a centre where e-waste can be dropped off and where trained staff can refurbish as appropriate and disassemble for scrap as necessary. This can be a source of revenue for the Centre.

All of the above are in many cases an unanswered need in communities big and small (except for the largest) across Canada. They are in need of a physical space for some of the activities and an organizational/management framework for hiring and supervising (mostly temporary/ student) staff. They can be a source of some revenue but are likely to require an on-going subsidy given the public service nature of many of their activities.

What the CIH does however, is to provide a focal point within small and rural communities and in urban communities with lower income, marginalized and immigrant populations a congregation point for digital access, training and collaboration. A place where youthful (and not so youthful) creative energies can be applied in the digital sphere and as well a place where those currently excluded from the digital economy and society with its benefits (but of course also its risks) can be guided, supported and enabled to become active and contributing participants. 